\title{
Material-specific memory loss in probable Alzheimer's disease
}

\author{
James T Becker, Oscar L Lopez, Jeanne Wess
}

\begin{abstract}
This study extends previous work analysing functional dissociations occurring in patients with Alzheimer's disease (AD) by demonstrating that material-specific memory loss is common. The pattern of neuropsychological dysfunction in 191 patients with probable AD was examined and $13 \%$ presented with material-specific memory loss. Thirteen patients had impaired immediate verbal recall, but normal non verbal recall and 12 had impaired non verbal recall and normal verbal memory. These patterns appeared to be related to a specific memory deficit and were probably not secondary to associated cognitive impairments. These data confirm earlier observations that the memory defect in AD can be materialspecific, and suggest that these patterns of impairment should be viewed as a focal sparing of function.
\end{abstract}

(F Neurol Neurosurg Psychiatry 1992;55:1177-1181)

The dementia associated with Alzheimer's disease (AD) must, by definition, involve two or more areas of cognitive function, ${ }^{12}$ but memory loss is generally the first and most pronounced of the symptoms and may exist in relative isolation. ${ }^{3}$ In spite of the extent of the cognitive impairment required for diagnosis, some patients with $\mathrm{AD}$ drawn from selective research samples have relative sparing of memory function for some types of information. ${ }^{4}$ Reduced verbal recall may be secondary to an impairment in lexical/semantic storage and retrieval, ${ }^{5}$ while a non verbal memory deficit (for example, complex figures and faces) may be due to a primary visuoconstructive $e^{4-5}$ or visuoperceptual impairment. ${ }^{6}$ To date it has not been possible to determine whether the material-specific memory loss could be due to a primary memory defect, or whether it only occurred secondary to an associated cognitive dysfunction. ${ }^{7}$

There were two purposes to our study. First, we wanted to determine whether we could identify individuals with material-specific memory loss among a sample of patients with $\mathrm{AD}$ who were not selected based on their pattern of neuropsychological defects. Second, we wanted to determine the extent to which defects in other information processing systems might contribute to, or be responsible for, the observed pattern of memory loss.

\section{Methods}

Subjects

Data were taken from the baseline visit of 194 $\mathrm{AD}$ patients and 103 normal elderly controls participating in the University of Pittsburgh Alzheimer's Disease Research Program from March 1983 to April 1988. The subjects were given an extensive neurobehavioural evaluation which has been described in detail previously. ${ }^{89}$ All patients and controls received neurological, psychiatric, and neuropsychological examinations, including the relevant laboratory and neuroimaging studies. All patients met the NINCDS/ADRDA criteria for probable $\mathrm{AD},{ }^{2}$ and none of the control subjects showed evidence of a progressive cognitive disorder. None of the patients with $\mathrm{AD}$ were referred to the programme because they had unusual patterns of cognitive loss. None of these patients had significant signs of cerebrovascular disease, and those with a score on the Hachinski Ischemic Scale ${ }^{10}$ greater than 4 , or evidence of possible infarction in two or more contiguous cuts on the CT scan of the brain were excluded from the cohort, and thus from this study. Twenty five of the patients with $\mathrm{AD}$ have since died, and necropsies including studies of the brain were carried out in 15. Twelve of these patients had "definite" $\mathrm{AD}$, which is consistent with reports from our centre ${ }^{11}$ as well as others. ${ }^{12}$ One of these three cases with $\mathrm{AD}$ was found to have CreutzfeldtJakob disease during the course of follow up which was confirmed at necropsy. A second case developed symptoms of progressive supranuclear palsy immediately before death, with accompanying pathological abnormalities. The third of these cases was found to have motor neuron disease without evidence of AD-like neuropathological abnormalities. The data from these three demented patients will not be considered in this report.

The control subjects were significantly younger $(p<0.001)$ and better educated $(p<0.001)$ than the patients with $\mathrm{AD}$ and were more likely to be men, although the latter difference was not significant $(p=0 \cdot 13)$ (see table 1). The patients with $\mathrm{AD}$ performed worse on the Mini-Mental State (MMS) ${ }^{13}$ examination $(p<0.001)$, and the Blessed assessment of functional abilities ${ }^{14}$ $(p<0.001)$. There was no abnormal elevation in the Hachinski rating ${ }^{10}(p=0.681)$.

Neuropsychological evaluation

The patients and controls were given an extensive battery of neuropsychological tests, 
Table 1 Characteristics of the study sample (mean SD)

\begin{tabular}{lll}
\hline & $\begin{array}{l}\text { Normal } \\
\text { Elderly } \\
(n=103)\end{array}$ & $\begin{array}{l}\text { Alzheimer's } \\
\text { Disease Patients } \\
(n=191)\end{array}$ \\
\hline Age & $63 \cdot 84$ & $71 \cdot 14$ \\
Education (years) & $(8 \cdot 27)$ & $(8 \cdot 73)$ \\
Sex (M/F) & $14 \cdot 33$ & $12 \cdot 30$ \\
Mini-Mental State & $(2 \cdot 90)$ & $(3 \cdot 01)$ \\
Blessed ADL Scale & $58 / 45$ & $128 / 66$ \\
(errors) & 28.98 & $19 \cdot 16$ \\
Hachinski Rating & $(1 \cdot 15)$ & $(5 \cdot 28)$ \\
& $0 \cdot 23$ & $6 \cdot 61$ \\
& $(1 \cdot 11)$ & $(4 \cdot 23)$ \\
& $1 \cdot 56$ & $1 \cdot 62$ \\
& $(0 \cdot 76)$ & $(1 \cdot 08)$ \\
\hline
\end{tabular}

and some of these data have been reported previously. 891516 Eleven neuropsychological measures assessing four cognitive domains were selected for analysis. They were: Memory: immediate and delayed recall of a story ${ }^{17}$ and a figure; ${ }^{151819}$ Visuospatial: figure copy, ${ }^{151819}$ visual form discrimination, ${ }^{20}$ draw and copy figures; ${ }^{2122}$ Lexical/Semantic: word generation, ${ }^{23}$ Boston naming test, ${ }^{22}$ easy verbal paired associates (for example, rose-flower) ${ }^{24}$ and Executive: verbal similarities, ${ }^{21}$ letter cancellation, ${ }^{25}$ digit span. ${ }^{17}$ The latter three sets of tests were selected based on the results of our previously published factor analyses and subgroup identification among patients with AD. ${ }^{816}$ For this study, we focused on two measures of memory-immediate recall of a short story ${ }^{17}$ and a modified Rey-Osterreith figure. ${ }^{151819}$ Measures of visuospatial, executive, and lexical/semantic functions were reduced to composite variables using procedures which we have described previously. ${ }^{89}$ The composite scores reflected an individual subject's deviation from their expected performance based on their age, education, and sex. The mean for the control subjects is approximately zero; that for the $\mathrm{AD}$ patients is negative.

\section{Results}

\section{Baseline}

Each patient with $\mathrm{AD}$ was classified on the basis of their immediate recall of the short story and the modified figure. The fifth percen-

Table 2 Classification of performance on memory tests

\begin{tabular}{lcc}
\hline & $\begin{array}{l}\text { Normal } \\
\text { Controls }\end{array}$ & $\begin{array}{c}\text { AD } \\
\text { Patients }\end{array}$ \\
\hline Both Tests Normal & 92 & 14 \\
Story Impaired/ Figure Normal & 5 & 13 \\
Story Normal/ Figure Impaired & 5 & 12 \\
Both Impaired & 0 & 151 \\
\hline
\end{tabular}

Table 3 Demographic information by patient subgroup mean (SD)

\begin{tabular}{|c|c|c|c|c|c|}
\hline & \multicolumn{4}{|c|}{$A D$ patients } & \multirow[b]{2}{*}{ Normal Control } \\
\hline & $\begin{array}{l}\text { Verbal } \\
\text { Impaired }\end{array}$ & $\begin{array}{l}\text { Non-Verbal } \\
\text { Impaired }\end{array}$ & $\begin{array}{l}\text { Both } \\
\text { Impaired }\end{array}$ & $\begin{array}{l}\text { Both } \\
\text { Normal }\end{array}$ & \\
\hline $\begin{array}{l}\text { Number } \\
\text { Age }\end{array}$ & $\begin{array}{l}13 \\
62 \cdot 34 \\
(7 \cdot 29)\end{array}$ & $\begin{array}{l}12 \\
70 \cdot 30 \\
(10 \cdot 67)\end{array}$ & $\begin{array}{l}151 \\
72 \cdot 05 \\
(7.92)\end{array}$ & $\begin{array}{l}14 \\
67 \cdot 76 \\
(11 \cdot 01)\end{array}$ & $\begin{array}{l}103 \\
63 \cdot 61 \\
(8 \cdot 22)\end{array}$ \\
\hline Education & $\begin{array}{l}13.69 \\
(3.33)\end{array}$ & $\begin{array}{l}12 \cdot 17 \\
(3.35)\end{array}$ & $\begin{array}{l}12.05 \\
(2.78)\end{array}$ & $\begin{array}{l}14.57 \\
(3.88)\end{array}$ & $\begin{array}{l}14 \cdot 33 \\
(2 \cdot 90)\end{array}$ \\
\hline $\begin{array}{l}\text { Sex }(M / F) \\
\text { Mini-Mental State }\end{array}$ & $\begin{array}{l}3 / 10 \\
23.46 \\
(4.99)\end{array}$ & $\begin{array}{l}11 / 1 \\
22.50 \\
(3.90)\end{array}$ & $\begin{array}{l}105 / 46 \\
18 \cdot 02 \\
(4 \cdot 54)\end{array}$ & $\begin{array}{l}6 / 8 \\
26 \cdot 79 \\
(2 \cdot 08)\end{array}$ & $\begin{array}{l}58 / 45 \\
29.02 \\
(1.09)\end{array}$ \\
\hline
\end{tabular}

tile for immediate recall of the story $(\leq 3.5)$ and the figure $(\leq 14 \cdot 0)$ by the control subjects was a cut-off for "abnormal" performance, based on the recommendation of McKhann, $e t$ $a l .{ }^{2}$ The resulting distribution of classification of the patients and controls is shown in table 2 . Using these criteria, 25/191 (13.1\%) of the patients with $\mathrm{AD}$ had material-specific memory loss: 13 with verbal impaired and nonverbal normal and 12 with nonverbal impaired and verbal normal. The characteristics of the patient subgroups are shown in table 3.

The performance of the patients and controls on the neuropsychological tests are shown in table 4 . There were significant differences among the four patient groups on the four memory measures $(p<0.001)$. Subsequent one-way analysis of variance with Tukey-HSD tests between the individual pairs of groups revealed that the performance of the Verbal Impaired patients on the immediate story recall was not significantly different from the Both Impaired patients $(p>0.05)$, but was significantly worse than that of the other two groups $(p<0.05)$. At delayed recall, the two focal groups did not differ from one another ( $p>0.05)$, but were significantly better than Both Impaired patients $(p<0.05)$. A similar pattern emerged when examining the recall of the figure. The Non Verbal Impaired patients did not differ from the Both Impaired group $(p>0.05)$, and were worse than either the Verbal Impaired or Both Normal groups $(p<0.05)$. At delayed recall, the Non Verbal Impaired patients were worse than the Verbal Impaired ( $<<0.05)$, but better than the Both Impaired group $(\mathrm{p}<0.05)$.

Analysis of the composite scores also revealed significant differences among the patient groups $(p<0.001)$. However, this was generally accounted for by the superior performance of the patients in the Both Normal group. In the case of the measures of Executive $(p>0.05)$, Lexical/Semantic $(p>0.05)$, and Visuospatial $(p>0.05)$ measures, there was no significant difference between the two focal impaired groups.

With both the Verbal Impaired and Non Verbal Impaired groups, there were no significant correlation between any of the composite variables and performance on the two immediate recall tasks. With the Verbal Impaired group, neither Executive $(r=0.004)$, Lexical/Semantic $(r=-0.08)$, nor Visuospatial $(r=0.35)$ scores correlated significantly with recall of the story. Similarly, among the Non Verbal Impaired patients, none of the correlations with immediate figure recall were significant (Executive: $r=-0.08$; Lexical/Semantic: $\quad r=0.25$; Visuospatial: $r=0.04$ ).

\section{Follow up}

One year after the initial evaluation, $127 \mathrm{AD}$ patients were retested, and 94 were able to provide sufficient neuropsychological test data to allow them to be classified in terms of the pattern of their memory loss. Each patient's performance was compared with that of 56 normal control subjects who had also com- 
Table 4 Neuropsychological Performance by Patient Subgroups mean (SD)

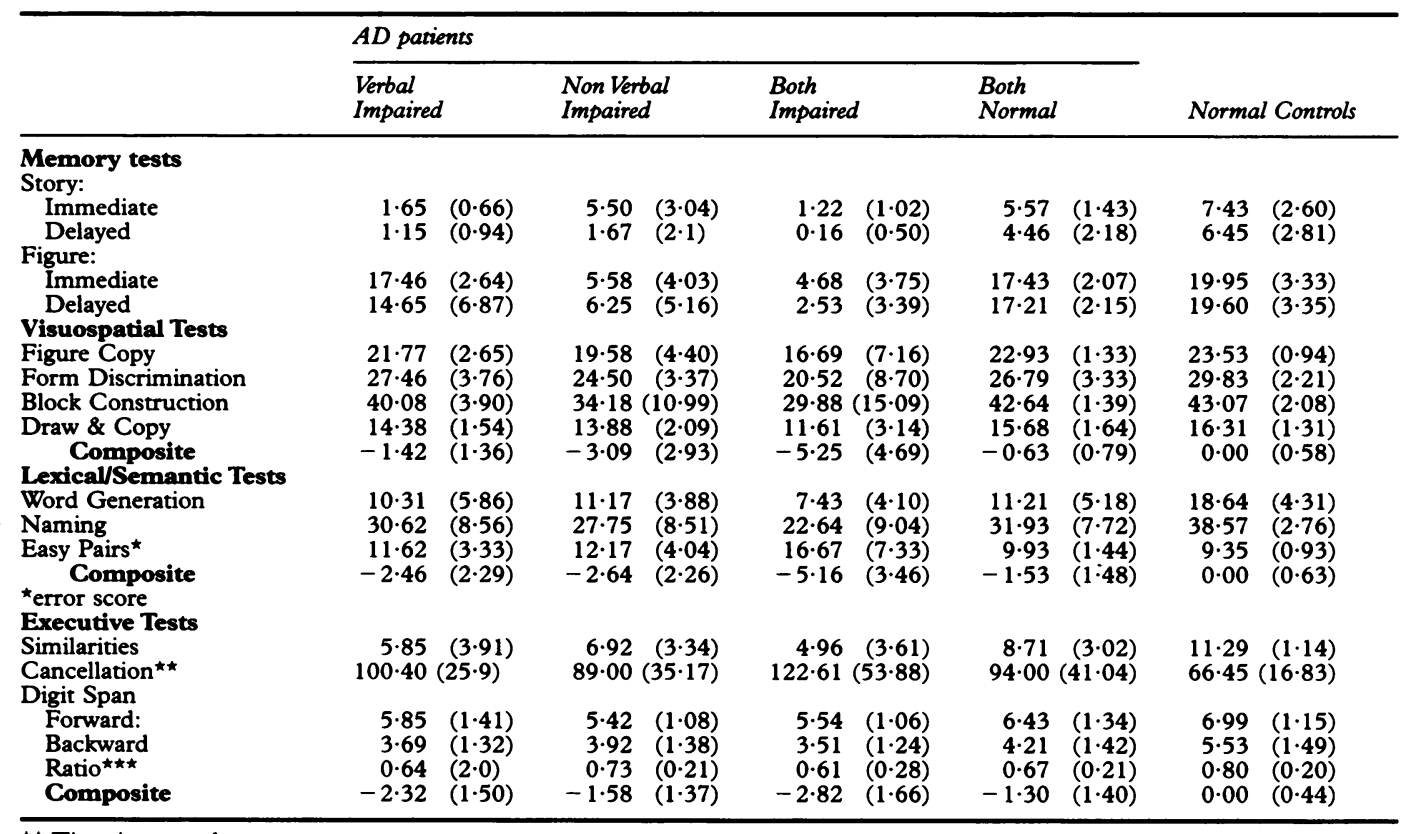

$\star \star$ Time in seconds

$\star \star \star$ Score used in composite.

pleted the second round of testing. A total of $14 / 25$ of the focal patients provided data, and 10 were classified as "Both Impaired" at follow up: 3/5 of the Verbal Impaired, and 7/9 of the Non Verbal Impaired. Four patients who were focal at both baseline and follow up ( 2 verbal, 2 non-verbal) had been relatively mildly impaired at the initial visit (that is, MMS = 26.0) and did not decline significantly during the subsequent year (that is, MMS = 25.5). The patients who were classified as non focal at follow up, but who had been "focal" at baseline, had a 4 point decline in their MMS scores (such as, 21·2-17.2).

Of the 80 patients who had been classified as non focal at baseline and were re-evaluated one year later, six developed a material-specific pattern of memory loss-four were Verbal Impaired and two Non Verbal Impaired. At baseline, all six of these patients were relatively mildly affected (MMS $=24 \cdot 34$ ), and one year later there was little change (MMS $=23 \cdot 84$ ). However, in all cases, the performance on one, but not both, of the memory measures declined below the cut-off score.

\section{Discussion}

These data demonstrate a relatively large number of $\mathrm{AD}$ patients with material-specific memory loss, and extend previous work analysing functional dissociations within $\mathrm{AD}$ patients. Approximately $13 \%$ of the patients had significant episodic memory loss restricted to either the verbal or non verbal domain at study entry. These material-specific memory impairments were independent of other cognitive disorders which could have limited performance on the memory tasks. The impairment in non verbal recall was not associated with a profound visuospatial deficit. Performance on visuoconstructional (for example, block design) or visuoperceptual (such as, form discrimination) tasks was equally impaired in both focal memory groups. Similarly, the verbal memory loss was not secondary to selective or disproportionately severe defects in lexical/semantic access or retrieval. Although the ability of the Verbal Impaired to recall the short story was as poor as that of the Both Impaired group, word generation, for example, was as good as that of the Both Normal patients (although still impaired to controls). Thus restriction of the ability to copy or discriminate visual forms, or to produce verbal items rapidly, could account for the pattern of impairment in the two groups of "focal" patients.

Neuropsychological studies have demonstrated that verbal episodic memory in patients with $\mathrm{AD}$ differs quantitatively, but not qualitatively from that of normal elderly individuals, ${ }^{4526-30}$ and have shown that patients with $\mathrm{AD}$ share several qualitative features with alcoholic amnesic syndromes. ${ }^{26}$ The episodic memory deficits in $\mathrm{AD}$ result from varying degrees of interaction of at least two independent factors: one, the inability to consolidate information, and the other, the inability or diminished capacity to encode information. ${ }^{45-32}$ Similarly, non verbal memory in patients with $A D$ has the same quantitative and qualitative pattern of impairment as verbal memory, when compared with normal controls and patients with amnesic syndromes. ${ }^{623233}$ However, previous reports have suggested that the severity of language impairment, ${ }^{32}$ visuoconstructional $^{4}$ and visuo-perceptual deficits ${ }^{6}$ can contribute to limiting the encoding of information to be remembered. In Martin's ${ }^{7}$ review of the data concerning subgroups of patients with $A D$, he noted that "patients with relatively focal cognitive impairment (for example, anomia) may have a material-specific learning deficit corresponding to their primary domain of cognitive dysfunction (such as 
verbal material)". However, analysis of the changes in the pattern of impairment of five patients with focal word-finding difficulties suggested that deterioration of memory proceeded independently from that of other cognitive functions. While these information processing defects clearly limit patients' ability to remember, they are not the only factors involved in the memory defect in $\mathrm{AD}$.

In this study, the material-specific memory loss noted was not primarily due to earlier processing impairments, but to a loss of memory functions. The patients were selected based on their memory task performance, and not their lexical/semantic or visuospatial abilities. Had they been identified based on these latter functions, ${ }^{6}$ then it would not have been possible to disentangle verbal skills from reduced verbal memory process (for example) as an explanation for a material-specific memory loss. However, because the patients were selected based on their memory performance, and because these patterns of impairment could not be explained by reduced verbal output or poor constructional skills, this strengthens our conclusion that these patterns reflect relatively spared/impaired memory functions.

The 29 patients ( 25 at baseline, 4 at follow up) identified here have profound episodic memory dysfunction restricted to either the verbal or nonverbal domains. These two subgroups of patients did not differ from one another in terms of either lexical/semantic or visual constructional skills or overall level of mental status. Their performance on the nonmemory tasks was also impaired relative to that of the normal controls. Thus it may be more accurate to view these two subgroups of patients as having a relative sparing of function, rather than a focal impairment at this point in the disease process. Among those in whom the disease progressed, they developed equivalent dysfunction in the two modalities. Among those whose mental status did not change, the pattern of impairment remained the same. When a patient developed a focal pattern of memory loss, they did so by declining in one domain (for example, verbal) without change in the other (for example, nonverbal). These longitudinal aspects of performance are critical for two reasons. First, by examining baseline performance in isolation, we have only a "snapshot" of the natural history of the dementia, and the results could be due to Type I and Type II errors of classification. The fact that the longitudinal data are internally consistent means that these findings are not due to chance alone. Second, the consistency of the changes in overall level of impairment, as well as the specific changes in memory function suggests that the materialspecific defects most likely reflect an underlying biological phenomena.

However, these focal patterns of impairment are probably not due to an underlying cerebrovascular disease. All of the patients were very carefully screened at baseline to eliminate those with either clinical or neuroradiological evidence of vascular lesions, and follow up neurological examinations were also inconsistent with new vascular events. Further, our analysis of $\mathrm{AD}$ patients with periventricular white matter lucencies identified on CT scans did not uncover similar functional dissociation (Lopez et al, personal communication).

Ten of the patients identified with focal patterns of impairment at baseline developed difficulties in both domains one year later. This is consistent with previous reports ${ }^{4}$ and raises an important clinical issue. That is, in patients who would otherwise meet diagnostic criteria for $\mathrm{AD}$ by virtue of a progressive course and the presence of an additional cognitive impairment, ${ }^{2}$ the finding of a material-specific memory loss should be sufficient to support the $A D$ classification. It also suggests that when using the APA's DSM-III-R ${ }^{1}$ criteria for Primary Degenerative Dementia the finding of a focal memory defect would be sufficient to meet the memory loss criteria.

This study has some limitations which may suggest direction for future research. First, the control subjects were younger and better educated than the patients. While this does not affect the composite variables since the ranges of age and education were similar in the two groups, and were accounted for in the regression model, it may have affected the identification of the focal patients. The cut-off scores were determined from the entire control sample, without regarding age or education, since the group was too small for all but the crudest breakdown. This may have resulted in an underestimation of focal impairment among the older and less educated patients. Thus estimates of the prevalence of these patterns of impairment, and conclusions about risk factors for exhibiting a focal impairment (such as, age) must be made with caution.

Furthermore, although we argue that the patterns of deficit seen here are due to material-specific defects (due to limitations in the test battery), we cannot differentiate this from a modality-specific impairment. Thus these impairments may be more accurately described as auditory-verbal and visual-non verbal, and further work must identify whether modality-specific defects can occur. Although conceptually we agree that a modality-specific impairment is possible in $\mathrm{AD}$, we are unaware of any such cases, and suggest that what we report represents material-specific impairments. Clearly additional study is necessary.

Finally, as with all studies of $\mathrm{AD}$, it is necessary to deal with the issue of the relationships among cognitive functions as the disease progresses. As the dementia worsened (as indicated by the MMS scores, for example), performance on the memory tests declined. However, as has been noted elsewhere, ${ }^{4834}$ the decline in cognitive functions is not monolithic, as might be suggested if one only examined summary mental status scores; different cognitive skills decline at different rates depending on the initial pattern of presentation. The findings in this study are consistent with this previous work but a careful study of the inter-relationships between cognitive processes examined in relative isolation, and 
overall verbal and cognitive functions would help to clarify the nature of the progression of the disease.

There is increasing agreement regarding the existence of subgroups of patients with $A D$ characterised by their pattern of cognitive impairment. ${ }^{7}$ The AD patients with focal deficits in this study provide important elements to the understanding of both the dementia process and normal human cognition. Nevertheless, the study of subgroups of patients with $\mathrm{AD}$ enrolled in longitudinal studies presents a special problem. Because the clinical criteria for the diagnosis of $\mathrm{AD}$ require that at least two areas of cognition be affected,,$^{12}$ it is difficult to identify these patient subgroups early in their development. However, the present data suggest that it is possible to identify important patient subgroups, and this kind of analysis should be useful in understanding the information processing defect associated with $\mathrm{AD}$, and perhaps, the pathophysiology of the disease.

These data were gathered by the Alzheimer Research Program (AGO3705) between 1983 and 1989 under the direction of $\mathrm{Dr}$ Francois Boller. Preparation of this manuscript was supported in part by funds from the National Institute on Aging AG05133). Ms D Pulkowski provided secretarial assistance. Drs R D Nebes and S DeKosky kindly read an earlier draft of this report.

1 American Psychiatric Association. Diagnostic and statistical manual of mental disorders, 3rd ed. Washington, DC:APA, 1987.

2 McKhann G, Drachman D, Folstein M, Katzman R, Price $D$, Stadlan E. Clinical diagnosis of Alzheimer's disease: Report of the NINCDS-ADRDA Work Group under the Report of the NINCDS-ADRDA Work Group under the auspices of Department of Health and Human Services Task For

3 Neary D, Snowden JS, Bowen DM, et al. Neuropsychological syndromes in presenile dementia due to cerebral atrophy. F Neurol Neurosurg Psychiatry 1986;49:163-74.

4 Martin A, Cox C, Brouwers P, Fedio P. A note on different patterns of impaired and preserved cognitive abilities and their relation to episodic memory deficits in Alzheimer's patients. Brain and Language 1985;26:181-5.

5 Martin A, Brouwers P, Cox C, Fedio P. On the nature of the verbal memory deficit in Alzheimer's disease. Brain and Language 1985;25:323-41.

6 Diesfeldt HFA. Recognition memory for words and faces in primary degenerative dementia of the Alzheimer's type and normal old age. F Clin Exp Neuropsychol 1990;12: 931-45.

7 Martin A. Neuropsychology of Alzheimer's Disease. The case for subgroups. In: Schwartz MF. Ed. Modular deficits in Alzheimer's type dementia. Cambridge, MA: Bradford/ MIT Press, 1990:143-75.

8 Becker JT, Huff FJ, Nebes RD, Holland A, Boller F. Neuropsychological function in Alzheimer's disease: patterns of impairment and rate of progression. Arch Neurol 1987;45:263-8.

9 Huff FJ, Becker JT, Belle SH, Nebes RD, Holland AD, Boller F. Cognitive deficits and clinical diagnosis of
Alzheimer's disease. Neurology 1987;37:1635-8.

10 Hachinski VC, Iliff LD, Zittka E, et al. Cerebral blood flow in dementia. Arch Neurol 1975;32:632-7.

11 Boller F, Lopez OL, Moossy J. Diagnosis of dementia: Clinicopathological correlations. Neurology 1989;39: 76-9.

12 Tierney MC, Fisher RH, Lewis AJ, Zorzitto ML, Snow WG, Reid DW, Nieuwstraten P. The NINCDS-ADRDA Working Group criteria for the clinical diagnosis of probable Alzheimer's disease: a clinicopathological study of 57 cases. Neurology 1988;38:359-69.

13 Folstein MF, Folstein SE, McHugh PR. Mini-Mental State: a practical method grading the cognitive state of patients for the clinician. $\mathcal{F}$ Psych Res 1975;12:189-98.

14 Blessed G, Tomlinson BG, Roth M. The Association between quantitative measures of dementia and of senile changes in the cerebral matter of elderly subjects. Psychiatry 1968;114:797-811.

15 Becker JT, Boller F, Saxton J, McGonigle-Gibson K. Normal rates of forgetting of verbal and non-verbal material in Alzheimer's disease. Cortex 1987;25:59-72.

16 Becker JT. Working memory and secondary memory deficits in Alzheimer's disease. $\mathcal{F}$ Clin Exp Neuropsychol 1988; 6:739-53.

17 Wechsler D. A standardized memory scale for clinical use. $f$ Psychol 1945;19:87-95.

18 Rey A. L'examen psychologique dans les cas d'encephalopathie traumatique. Arch Psychologie 1941;28:286-340.

19 Osterreith PA. Le test de copie d'une figure complexe. Arch Psychologie 1944;30:206-56.

20 Benton AL, Hamsher K, Varney NR, Spreen O. Contributions to neuropsychological assessment: a clinical manual. tions to neuropsychological assessment: a clinit

21 Wechsler D. Wechsler Adult Intelligence Scale Manual. New York: Psychological Corporation, 1955.

22 Goodglass H, Kaplan E, Weintraub S. The assessment of aphasias and related disorders, 2nd ed. Philadelphia: Lea and Fabiger, 1983.

23 Benton AI. Differential behavioral effects in frontal lobe disease. Neuropsychologia 1968;6:53-60.

24 Inglis J. An experimental study of learning and "memory function" in elderly psychiatric elders. I Ment Sci 1957 103:796-803.

25 Diller L, Ben-Yishay Y, Gerstman LJ, Goodkin R, Gordon W, Weinberg A. Studies in cognition and rehabilitation in hemiplegia (Rehabilitation monograph 50). New York, New York University Press, 1979.

26 Butters N, Granholm E, Salmon DS, Grant I, Wolfe J. Episodic and semantic memory. A comparison of amnestic and demented patients. F Clin Exp Neuropsychol 1986;9:479-97.

27 Butters N, Albert MS, Sax DS, Miliotis P, Nagode J, Sterste $A$. The effect of verbal mediators on the pictorial memory of brain damaged patients. Neuropsychologia 1983;21: 307-23.

28 Kaszniak AW, Poon LW, Riege W. Assessing Memory Deficits: An information-processing approach. In: Hackett T, Poon LW, eds. Handbook for clinical memory assessment of older adults. Hyattsville, MD: American Psychological Association, 1988:168-88.

29 Kopelman MD. Multiple memory deficits in Alzheimertype dementia: Implications for pharmacotherapy. Psychol Med 1985;15:527-41.

30 Wilson RS, Bacon LD, Fox SH, Kaszniak AW. Primary memory and secondary memory in dementia of Alzheimer type. $\mathcal{f}$ Clin Exp Neuropsychol 1983;5:337-44.

31 Morris RG, Baddeley AD. Primary working memory functioning in Alzheimer's type dementia. F Clin Exp Neuropsychol 1987;10:279-96.

32 Wilson RD, Bacon LD, Kramer RL, Fox SH, Kaszniak AW. Word frequency effect and recognition memory in dementia of Alzheimer type. $f$ Clin Exp Neuropsychol 1983;5:97-104.

33 Kopelman MD. Rates of forgetting in Alzheimer-type dementia and Korsakoff's syndrome. Neuropsychologia 1985;23:623-8.

34 Becker J, Bajulaiye O, Smith C. Longitudinal analysis of a two-component model of the memory deficit in Alzheimer's disease. Psychol Med 1992;22:437-46. 